\title{
The impact of metakaolin, silica fume and fly ash on the temperature resistance of high strength cement paste
}

\author{
Nabil Abdelmelek ${ }^{1} \cdot$ Eva Lubloy $^{1}$ (D) \\ Received: 20 August 2020 / Accepted: 17 February 2021 / Published online: 26 March 2021 \\ (c) The Author(s) 2021
}

\begin{abstract}
The effects of elevated temperatures on the properties of high-strength cement paste (HSCP) based on metakaolin (MK), silica fume (SF), and fly ash (FA) were studied in the current experimental research. The resistance of HSCP against elevated temperatures was evaluated as well. The new method is expressed by the total area under each curve of strength, known as "temperature resistance", is adopted. Results of the HSCP mixtures containing MK, SF, and FA with replacements ratios of $9 \%, 6 \%$ and $15 \%$ have shown excellent temperature resistance at all levels of maximum temperatures, respectively. Properties added to HSCP by these supplementary cementitious materials (SCM) such as decreasing the amount of $\mathrm{CaO}$ and increasing the amounts of $\mathrm{SiO}_{2}$ and $\mathrm{Al}_{2} \mathrm{O}_{3}$ have minimized the harmful effects of the use of pure ordinary Portland cement (OPC) at elevated temperatures. The results have shown also that the grinding fineness of OPC influences the amount of optimum replacement of the used SCM on HSCP at elevated temperatures. Hence, the amount of optimum replacement of MK blended with CEM I $42.5 \mathrm{~N}$ was $9 \%$ whereas, the amount of optimum replacement of MK blended with CEM I $52.5 \mathrm{~N}$ shifted to $3 \%$. Finally, the fineness of cement of $4500 \mathrm{~cm}^{2} \mathrm{~g}^{-1}$ has shown a better-elevated temperature resistance compared to the cement with a fineness of $4000 \mathrm{~cm}^{2} \mathrm{~g}^{-1}$ in case of using pure OPC.
\end{abstract}

Keywords High strength cement paste $\cdot$ Metakaolin $\cdot$ Silica fume $\cdot$ Fly ash $\cdot$ Grinding fineness $\cdot$ Elevated temperature

\section{Introduction}

The production of high strength concrete (HSC) has been one of the essential incentive research for engineers and researchers in terms of enhancing the performance and durability of concrete [1]. The American Concrete Institute (ACI) specifies the compressive strength grade of $40 \mathrm{MPa}$ as the minimum value to be considered as HSC [2]. Moreover, various factors are required in the design of the HSC mixture such as the low water to binder ratio (w/b) and the high content of binder [1,3]. Supplementary cementitious materials (SCM) are a type of binder that can be defined as aluminous and siliceous materials, obtained naturally or artificially which added to the ordinary Portland cement (OPC) in

Eva Lubloy

lubloy.eva@epito.bme.hu

Nabil Abdelmelek

abdelmelek.nabil@epito.bme.hu

1 Department of Construction Materials and Technologies, Faculty of Civil Engineering, Budapest University of Technology and Economics, Budapest 1521, Hungary order to improve the properties of concrete. In the presence of moisture, SCM react with the product of cement hydration to produce extra strength in the form of calcium silicate and calcium aluminate silicate hydrates [4]. The common types of SCM are silica fume (SF), fly ash (FA), ground granulated blast-furnace slag (GGBS), and metakaolin (MK) [4-6]. Despite the uncountable advantages of the application of HSC in terms of strength, stiffness, durability, and economic benefits, HSC showed undesirable performance at elevated temperature $[2,7,8]$. Thus, the evaluation of elevated temperatures resistance of HSC is of great importance.

The adoption of SCM in cement generally has a good impression in the literature from the context of mechanical properties of HSC after exposure to elevated temperatures [9-12]. Behnood and Ziari [3] investigated the effect of using SF with different replacements, i.e., $0 \%, 6 \%$, and $10 \%$ on the properties of HSC after exposure to elevated temperature, concluding that the amount of SF optimum replacement is $6 \%$. Hertz [13] concluded that the replacement of cement with $10 \%$ of SF is the upper limit to avoid the occurrence of spalling. From another hand, Poon et al. (2003) have experimentally studied the performance of 
concrete prepared by MK at elevated temperature. Results showed that concrete containing high replacements of MK (20\%) suffered at elevated temperatures, showing a significant loss in the mechanical properties [14]. The performance of concrete containing FA has been investigated at elevated temperatures as well. The properties of concrete are found to be improved in the presence of FA after exposure to elevated temperatures [15].

The behaviour of HSC at elevated temperatures depends on several parameters such as the amount of $w / b$ ratio, type of SCM, amount of calcium-silicate-hydrates (CSH), amount of $\mathrm{Ca}(\mathrm{OH})_{2}$, degree of hydration, rate of heating, and time of exposure $[9,16]$. Besides, the quality of HSC is fundamentally affected by the chemical-mineral properties of the used cement as well as its fineness and grading [9, 17-19]. However, no available studies have investigated the influence of cement fineness on the amount of optimum replacement of SCM at elevated temperatures exposure. In addition, the significance of this study is clear since the results testing, comparing, and discussing of the effects of the three SCM, i.e., MK, SF, and FA materials on highstrength cement paste (HSCP) after the exposure to elevated temperatures is presented herein.

\section{Significance of the research}

The literature of the performance of HSC incorporated by different types of SCM in the case of fire is common. However, the studies that outline the comparison of them from the perspective of temperature resistance are infrequent. At the current study, adoption of short incremental replacements of SCM as a binder is considered. This is important to provide more accuracy of the selection of the optimum replacement. It also investigates the impact of changing the fineness of cement in terms of temperature resistance and optimum replacement. Finally, providing HSCP with high capacity against elevated temperatures is the objective of the current experimental work.

\section{Experimental program}

A total of 22 mixtures of HSCP were prepared and tested. The prepared mixtures are divided into two groups as shown in Fig. 1. The first group is prepared by CEM I $42.5 \mathrm{~N}$ (the right branch of Fig. 1) consisting of three subgroups including SF, MK, and FA. Mixtures in the second group were made with CEM I $52.5 \mathrm{~N}$ (the left branch of Fig. 1) incorporated only by MK. Each type of SCM at both branches has six different mixtures depending on the replacement ratios of the used SCM. The different replacements ratios of cementitious materials to the cement were

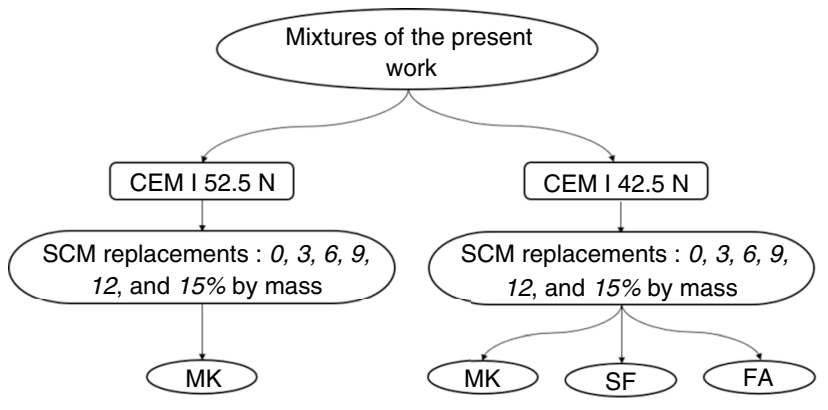

Fig. 1 The parameters of the experimental work

Table 1 Experimental matrix with detailed varied parameters

\begin{tabular}{lll}
\hline \multicolumn{3}{l}{ Mixture proportion $/ \mathrm{kg} \mathrm{m}^{-3}$} \\
\hline SCM dosages & CEMI & Water \\
\hline $0 \%$ & 480 & 144 \\
$3 \%$ & 465.6 & 144 \\
$6 \%$ & 451.2 & 144 \\
$9 \%$ & 436.8 & 144 \\
$12 \%$ & 422.4 & 144 \\
$15 \%$ & 408 & 144 \\
\hline
\end{tabular}

kept constant for the three SCM (SF, MK, and FA); the replacements were $0 \%, 3 \%, 6 \%, 9 \%, 12 \%$, and $15 \%$ by mass. Table 1 shows the proportions the cement paste mixtures for a type of SCM. Finally, the w/b ratio of 0.30 was constant for all mixtures and constant amount of binder of $480 \mathrm{~kg} \mathrm{~m}^{-3}$.

\section{Materials}

The used types of cement through the current study were CEM I 42.5 N and CEM I 52.5 N (Duna-Dráva Cement, Heidelberg Cement Group), following the standards: MSZ EN 196-2:2013; MSZ EN 525-12:2014 [20, 21]. The crystalline phases of CEM I could be identified as: $\mathrm{Ca}_{3} \mathrm{SiO}_{5}\left(\mathrm{C}_{3} \mathrm{~S}\right.$, alite, hatrurite) as main crystalline component; $\mathrm{Ca}_{2} \mathrm{SiO}_{4}\left(\mathrm{C}_{3} \mathrm{~S}\right.$, belite, larnite) presence cannot be excluded; $\mathrm{CaSO}_{4} \cdot 2 \mathrm{H}_{2} \mathrm{O}$ ( $\mathrm{CSH}_{2}$, gypsum); $\mathrm{Ca}_{4} \mathrm{Al}_{2} \mathrm{Fe}_{2} \mathrm{O}_{10}\left(\mathrm{C}_{4} \mathrm{AF}\right.$, brownmillerite). In addition, the used mixing water was tap water complied with the standard requirement of BS EN 1008:2002. The used SF, MK and FA throughout the experimental program are mostly amorphous materials [22]. The chemical and physical properties of the used materials are presented in Table 2 .

\section{Heating and testing procedures}

The procedures of heating and testing have been prepared as follows: 

and physical properties of tested materials
Table 2 Chemical compositions

\begin{tabular}{|c|c|c|c|c|c|}
\hline \multirow[t]{2}{*}{ Measured property } & CEM I $52.5 \mathrm{~N}$ & CEM I $42.5 \mathrm{~N}$ & MK & SF & FA Class F \\
\hline & \multicolumn{5}{|c|}{ Oxide compositions/\% (by mass) } \\
\hline $\mathrm{SiO}_{2}$ & 20.59 & 19.84 & $52-53$ & 96.43 & 54.4 \\
\hline $\mathrm{Al}_{2} \mathrm{O}_{3}$ & 5.55 & 5.38 & $43-44$ & 0 & 26.5 \\
\hline $\mathrm{Fe}_{2} \mathrm{O}_{3}$ & 3.21 & 3.22 & $<1$ & 0.073 & 4.8 \\
\hline $\mathrm{CaO}$ & 65.02 & 64.90 & $<0.5$ & 0.78 & 3.5 \\
\hline $\mathrm{MgO}$ & 1.44 & 1.38 & $<0.4$ & 0.70 & 2.5 \\
\hline $\mathrm{SO}_{3}$ & 2.88 & 2.97 & - & 0.038 & 1.7 \\
\hline $\mathrm{K}_{2} \mathrm{O}$ & 0.78 & 0.78 & $<1$ & 1.28 & 0.6 \\
\hline $\mathrm{Cl}$ & 0.0048 & 0.0048 & - & - & - \\
\hline $\mathrm{Na}_{2} \mathrm{O}$ & - & - & $<0,1$ & - & 0.4 \\
\hline $\mathrm{TiO}_{2}$ & - & - & $<1$ & - & 1.5 \\
\hline Loss on ignition/\% & & 3.0 & 1.59 & 2.8 & 2.3 \\
\hline Density $/ \mathrm{g} \mathrm{cm}^{-3}$ & 3.17 & 3.13 & 2.6 & 2.2 & 3.13 \\
\hline $\begin{array}{l}\text { Specific surface area/ } \\
\mathrm{cm}+2 \mathrm{~g}^{-1}\end{array}$ & 4500 & 4000 & 24,000 & 20,000 & 20,000 \\
\hline
\end{tabular}

- Mixing all the ingredients in a mixer then pouring the paste into $30-\mathrm{mm}$ cubes for the compressive strength tests.

- The cubes have been de-moulded after $24 \mathrm{~h}$ of the casting process, then placed in water.

- After 7 days of curing, the cubes have been removed from the water tank then stored in laboratory conditions $\left(20 \pm 2{ }^{\circ} \mathrm{C}\right.$ and approximately $35 \%$ of relative humidity).

- At the age of 3 months, the testing program of specimens has been conducted.

- The heating program has been applied for each of the three specimens from the same mixture, by heating them to the target temperature $(20,150,300,400,500,800$ and $900^{\circ} \mathrm{C}$ ) for two hours of exposure duration.

- After $2 \mathrm{~h}$ of fixed-temperature exposure, the cubes have been left in the lab condition $\left(20 \pm 2{ }^{\circ} \mathrm{C}\right.$ and approximately $35 \%$ of relative humidity) to be naturally cooled down. Then, finally, after $24 \mathrm{~h}$ of cooling down, load testing is applied.

- Noting that the heating curve of the used electric furnace was set up according to the standard fire ISO 834 curve for buildings, as shown in Fig. 2 [23].

\section{Thermo-gravimetric program (TG)}

TG investigation defines the ranges of various thermal decompositions of different hardened paste products and phases with simultaneous estimation of the mass loss in static condition. Moreover, changes in phases are controlled by means of TG/DTG/DTA using MOM Derivatograph-Q $1500 \mathrm{D}$ TG/DTA instrument. During the measurements, $\mathrm{Al}_{2} \mathrm{O}_{3}$ is the reference material considering the mass of the sample to be $300 \mathrm{mg}$. The heating rate of samples was $10{ }^{\circ} \mathrm{C} \mathrm{min}^{-1}$ up to $1000{ }^{\circ} \mathrm{C}$ in air atmosphere.

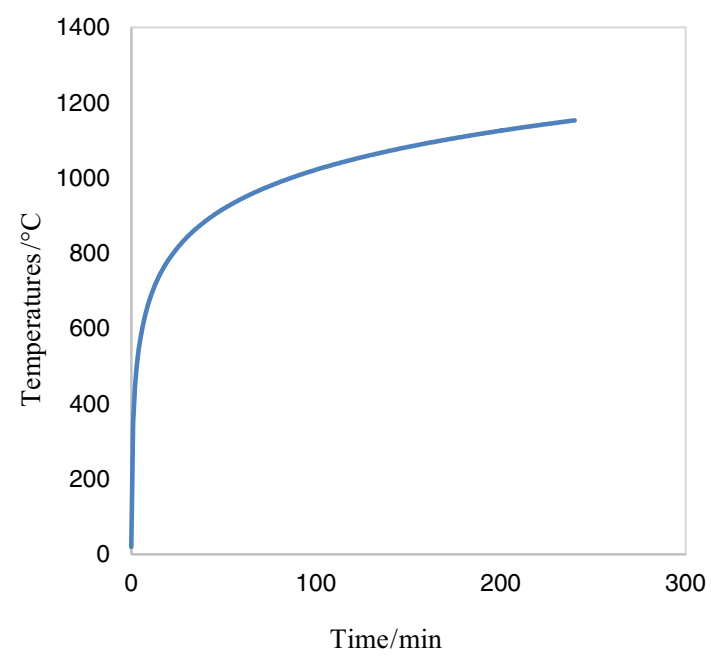

Fig. 2 ISO-834 fire curve

Thermo-gravimetric samples are ground to a fine powder and measured by TG/DTA to ensure the soundness of samples from carbonation. The tested powders were taken from specimens of ambient temperatures $20{ }^{\circ} \mathrm{C}$ and selected from the core of specimens. The investigated powders are taken from the samples that showed high performance after exposure to elevated temperatures (optimum replacements of SCM), as well as the mixtures of pure OPC (reference) for the comparison. In the case of the thermo-analytical test results are determined by Winder software (Version 4.4). The TG/DTA studies were carried out when the samples have the age of 90 days. 


\section{Scanning electron microscope (SEM)}

SEM investigations have helped to discover and understand the microstructure properties of hardened cement paste containing different ratios of SCM (reference and optimum mixtures) before and after the exposure to high temperatures. After the compressive strength test, the cores of the cross-section of the specimens were coated with gold spray with a duration of $30 \mathrm{~s}$ in a vacuum chamber, thereafter the samples are investigated under SEM.

\section{Computed tomography (CT) measurement}

Slice image or tomography is a Greek-originated word. Tomographic images are obtained from a large series of twodimensional X-ray images were taken in a different direction. In addition, these cross-sectional images can be combined into a three-dimensional image of the specimens inside the structure. The samples containing different ratios of SCM (reference and optimum) have been investigated under CT equipment to evaluate the distribution and the volume of pores in hardened cement paste.

\section{Results and discussions}

\section{Physical characteristic of the used powders}

Figure 3 shows the microstructure of the used powders under SEM investigation. The differences in the microstructure are defined by the size and shape of the particles, which significantly depending on the type of the material.

The particles of the used SCM are very small compared to the OPC particles, resulting in high specific surface area, particularly SF that contains hundreds of small spherical particles that together reach the size of one particle of OPC. FA is a glassy spherical particle, hollow inside with different sizes. As shown in Fig. 3, MK is a very fine material characterized by elongated shape in the form of micro fibres. On the other hand, OPC contains coarse particles with relatively smooth surface. The observed difference between CEM I 42.5 and CEM I 52.5 after many investigated points by SEM is the size of particles. Comparing both types of cement, CEM I 42.5 is relatively coarser than CEM I 52.5. Finally, by knowing the morphology and microstructure of powders could help to understand the behaviour of cement paste blended by different types of SCM after exposure to elevated temperatures.

\section{Results after exposure to elevated temperatures}

\section{Effect of SCM on the surface cracking}

Propagation of the cracks can be observed after exposure to elevated temperature, (see Fig. 4). By increasing the level of temperatures, hardened cement paste specimens subjected to chemical and physical changes in different temperatures levels. This sequence of transformations induces internal stresses and simultaneously resulting in the formation of cracks. Figure 4 shows the surface cracking of MK mixtures only after exposure to 500 and $800{ }^{\circ} \mathrm{C}$. There were no cracks observed on the surface of all cubes that exposed to temperatures up to $400{ }^{\circ} \mathrm{C}$ regardless of the composition of the mix ingredients. However, the number and size of cracks strongly grew after exposure to elevated temperature, i.e., $800{ }^{\circ} \mathrm{C}$ in case of mixtures with $0 \%$ of $\mathrm{MK}$ content, and in less degree for mixtures contain more amounts of MK. This could be contributed to the chemical processes occurring in the HSCP with $0 \% \mathrm{MK}$ (which contains a high content of $\mathrm{Ca}(\mathrm{OH})_{2}$ compared to mixtures that contain $\left.\mathrm{MK}\right)$. The disintegration of $\mathrm{Ca}(\mathrm{OH})_{2}$ between 450 and $600{ }^{\circ} \mathrm{C}$ is very rapid and part of the decomposition of $\mathrm{CSH}$ sheets occur at different phases up to $800{ }^{\circ} \mathrm{C}$. Moreover, after cooling the specimens, $\mathrm{CaO}$ rehydrates with humidity can cause $44 \%$ of volume increasing and considerably increase the extent of the crack development [24]. Therefore, the number of cracks is increased as a function of time after cooling down.

\section{Impact of different types of SCM on compressive strength results}

The results of the residual compressive strength after elevated temperature exposure are presented in this section. All specimens were tested at the age of 90 days, which is recommended by RILEM with the purpose to reflect the performance of real structures at the fire.

Relative residual compressive strength as a function of temperature is calculated as follows: division of the value of residual compressive strength for each single temperature level by the strength of the same mixture at $20^{\circ} \mathrm{C}$, the values of compressive strength at $20{ }^{\circ} \mathrm{C}$ for all mixtures are presented in Table 3 . Since the results in the figures give a large number of curves (Figs. 5-8) that increase the complexity of comparing the results, results were expressed through the calculation of the area under the curve of the relative residual compressive strength $\left(20-900{ }^{\circ} \mathrm{C}\right)$. As a result, obtained data are expressed by a new approximate parameter, called temperature resistance, all mixtures are presented in Fig. 9.

Figure 5 shows the development of relative residual compressive strength as a function of temperature; six different replacements of the cement (CEM I $42.5 \mathrm{~N}$ ) by amounts of MK are presented, i.e., $0 \%, 3 \%, 6 \%, 9 \%, 12 \%$, and $15 \%$. According to Fig. 5, HSCP containing MK shows a higher relative residual compressive strength values compared to the reference HSCP (Ref 0\%). A significant drop in the relative residual compressive strength after $400^{\circ} \mathrm{C}$ was observed for the reference mixture (Ref $0 \%$ ). The dehydration of $\mathrm{Ca}(\mathrm{OH})_{2}$ between 450 and $550{ }^{\circ} \mathrm{C}: \mathrm{Ca}(\mathrm{OH})_{2} \rightarrow \mathrm{CaO}+\mathrm{H}_{2} \mathrm{O} \uparrow$ 


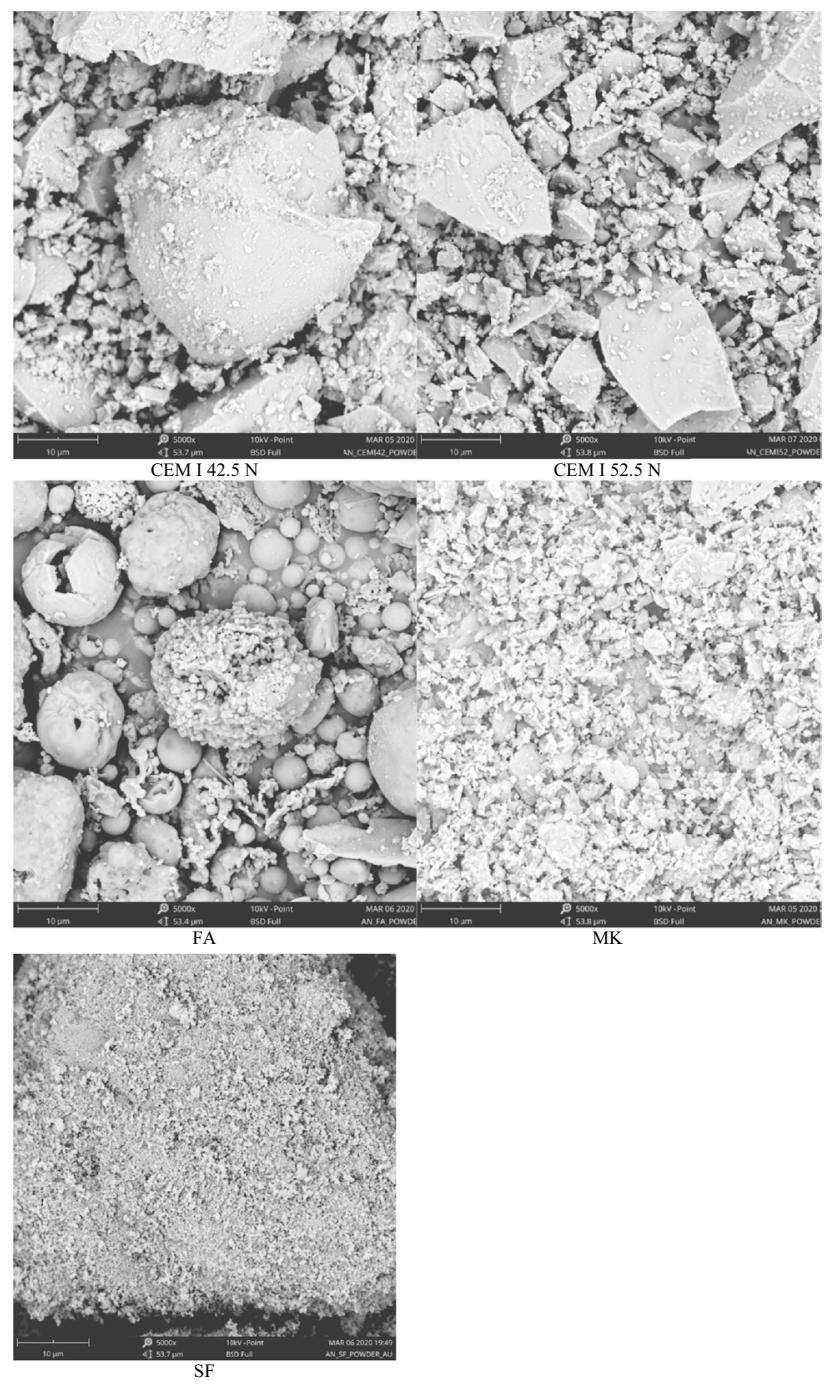

Fig. 3 Microstructure morphology of the used powders by SEM

could explain this phenomenon [25]. From another hand, the mixture containing $9 \%$ of MK shows the highest relative residual compressive strength, improving the relative residual compressive strength of HSCP with 52\% and 39\% compared to the reference mixture (Ref $0 \%$ ) at 500 and $800{ }^{\circ} \mathrm{C}$, respectively. This improvement is due to the pozzolanic reaction provided by MK, besides the properties of $\mathrm{MK}$, which featured by low content of $\mathrm{CaO}$, and high constituents of $\mathrm{AL}_{2} \mathrm{O}_{3}$ and $\mathrm{SiO}_{2}$ [25].

Figure 6 shows the results of relative residual compressive strength of HSCP as a function of the temperature; six replacements of cement by SF are presented, i.e., $0 \%, 3 \%$, $6 \%, 9 \%, 12 \%$, and $15 \%$. The relative residual compressive strength values of the mixtures containing $6 \%$ and $9 \%$ of SF are higher than counterparts' specimens with different amounts of SF (shown in Fig. 6). Incorporation of cement by $6 \%$ and $9 \%$ improves the relative residual compressive strength of HSCP with $73 \%$ and $68 \%$ more than the reference mixture at $500{ }^{\circ} \mathrm{C}$ and the difference is $73 \%$ and $43 \%$ at $800{ }^{\circ} \mathrm{C}$, respectively. This improvement is related to the consumption of $\mathrm{Ca}(\mathrm{OH})_{2}$ in addition to the internal autoclaving effect which forming additional hydration of cement. Moreover, the pozzolanic reaction of SF with $\mathrm{Ca}(\mathrm{OH})_{2}$ produces additional strength in the form of $\mathrm{CSH}$ [4]. Mixtures containing $12 \%$ and $15 \%$ of SF show a lower compressive strength in comparison with mixtures of $6 \%$ and $9 \%$ of SF. This could be attributed to the high dense structure provided at high SF replacements which induce internal cracking.

Relative residual compressive strengths of HSCP containing different replacements of FA are shown in Fig. 7. The relative residual compressive strengths increase with the increase of FA replacements. Furthermore, the inclusion of $15 \%$ of FA revealed the highest relative residual compressive strength at all temperature levels, in which strength improvement values are $71 \%$ and $36 \%$ more than the reference value (Ref $0 \%$ ) at $500{ }^{\circ} \mathrm{C}$ and $800{ }^{\circ} \mathrm{C}$, respectively.

\section{Impact of cement fineness on the behaviour of SCM}

The relative residual compressive strength of HSCP (type CEM I $52.5 \mathrm{~N}$ ) incorporated only by MK are graphically presented in Fig. 8. The highest relative residual compressive strength was obtained from the mixture that containing $3 \%$ of MK for all temperature levels. The relative residual compressive strength is enhanced by $41 \%$ and $32 \%$ compared to the reference at $500{ }^{\circ} \mathrm{C}$ and $800{ }^{\circ} \mathrm{C}$, respectively.

This study highlights the two types of cement incorporated with MK that have been shown before in Figs. 5, and 11. It was found that there is a significant effect of changing the type of cement fineness on the performance of MK at elevated temperature. Results showed that the amount of optimum replacement value of MK with CEM I $42.5 \mathrm{~N}$ was $9 \%$ then it has been shifted to $3 \%$ by changing the cement fineness by using CEM I $52.5 \mathrm{~N}$. Finally, the findings of the current study are summarized in Table 4. In general, using any of the three materials; MK, SF or FA has benefits in terms of enhancing temperature resistance of HSCP. Furthermore, SF increases the temperature resistance more than MK and FA by $8 \%$ and 7\%, respectively. This result could be related to the high content of $\mathrm{SiO}_{2}$ included in the composition of SF as well as due to the very small SF particles. The highest replacement by cement was achieved by FA (15\%) compared to the other pozzolanic materials. This could be due to the shape of FA particles, which is hollow and porous inside, contributing for the enhancement of HSCP at elevated temperature by working as micro pores. 

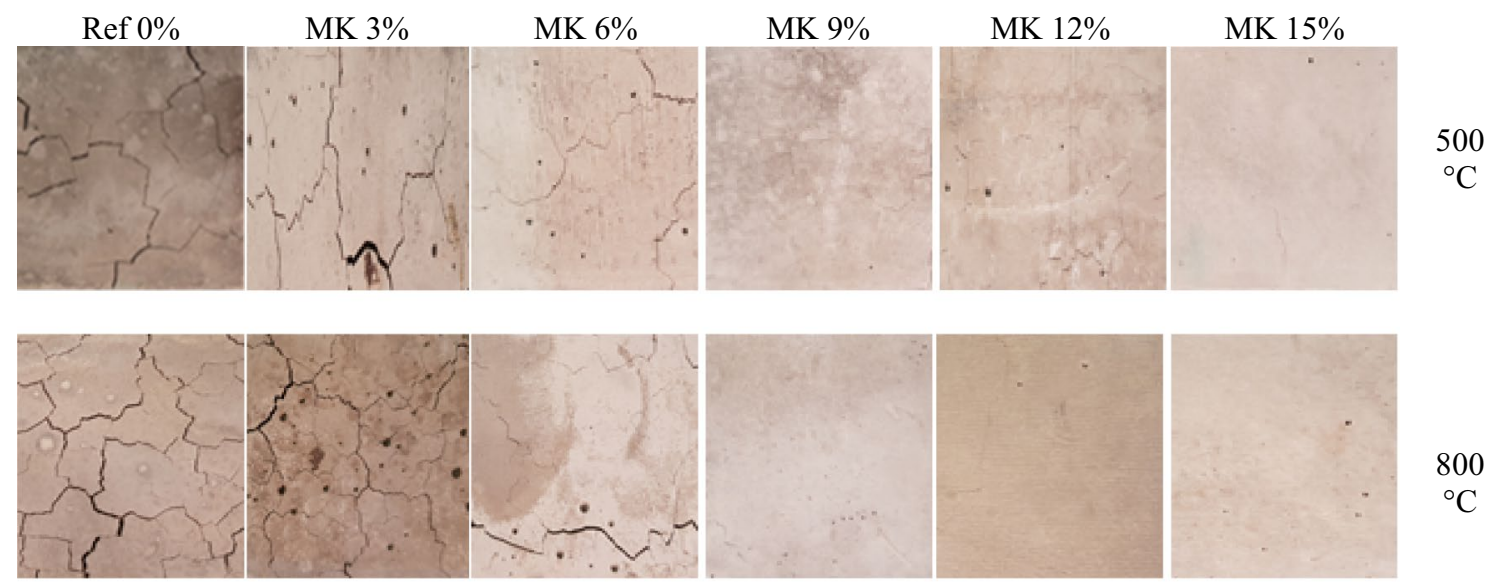

Fig. 4 Effect of MK dosages on the development of surface cracking as a result of the elevated temperature

Table 3 Compressive strength values at $20^{\circ} \mathrm{C}(\mathrm{MPa})$

\begin{tabular}{lcrrl}
\hline Dosages/\% & MK/CEM I 42.5 & MK/CEM I 52.5 & \multicolumn{1}{l}{ SF } & \multicolumn{1}{l}{ FA } \\
\hline 0 & 107.00 & 110.62 & 107.00 & 107.00 \\
3 & 89.40 & 82.17 & 112.62 & 126.72 \\
6 & 82.01 & 96.65 & 93.36 & 109.17 \\
9 & 86.24 & 119.68 & 94.58 & 123.02 \\
12 & 118.94 & 102.72 & 91.08 & 118.14 \\
15 & 94.22 & 93.27 & 92.64 & 94.25 \\
\hline
\end{tabular}

Figure 9 shows the calculated temperature resistance results of all mixtures from Figs. 5-8. The mixtures of MK prepared by CEM I $42.5 \mathrm{~N}$ showed that using $9 \%$ of MK has the highest temperature resistance that improved by $152 \%$ compared to the reference mixture (Ref $0 \%$ ). The temperature resistance of HSCP containing SF, indicating that the use of SF is generally preferred. The maximum increase in the temperature resistance of the relative residual compressive strength using SF compared to the reference mixture is $160 \%$ achieved by mixture containing $6 \%$ replacement. As illustrated in Fig. 9, it can be observed that all FA mixtures have higher temperature resistance than the reference mixture. The temperature resistance has reached the maximum value by $15 \%$ of FA with an extra increase of $153 \%$ from the reference value. In the other hand, MK mixtures of CEM I $52.5 \mathrm{~N}$ have shown that the incorporation of $3 \%$ of MK achieved the highest temperature resistance by $156 \%$ of increase compared to the reference. Finally, the comparison between reference mixtures for both of cement types, i.e., CEM I $42.5 \mathrm{~N}$ and CEM I $52.5 \mathrm{~N}$ have been conducted. Results show that temperature resistance of the mixture containing CEM I $52.5 \mathrm{~N}$ is higher than mixture containing CEM I $42.5 \mathrm{~N}$. This conclusion could be attributed to the high fineness of CEM I $52.5 \mathrm{~N}\left(4500 \mathrm{~cm}^{2} \mathrm{~g}^{-1}\right)$.

\section{Thermo-gravimetric results}

Results of the loss of mass using TGA/DTG analysis of MK unheated samples (before exposure to elevated temperatures)
Fig. 5 Relative residual compressive strength of HSCP incorporated with $\mathrm{MK}$ as a function of temperature

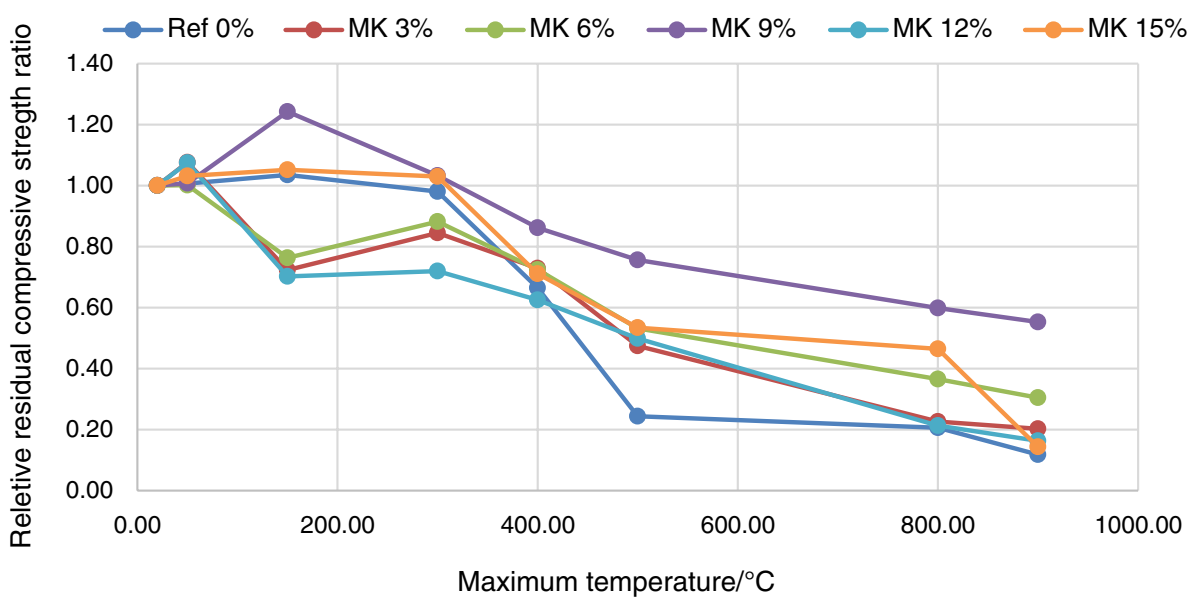


Fig. 6 Relative residual compressive strength of HSCP incorporated with $\mathrm{SF}$ as a function of temperature

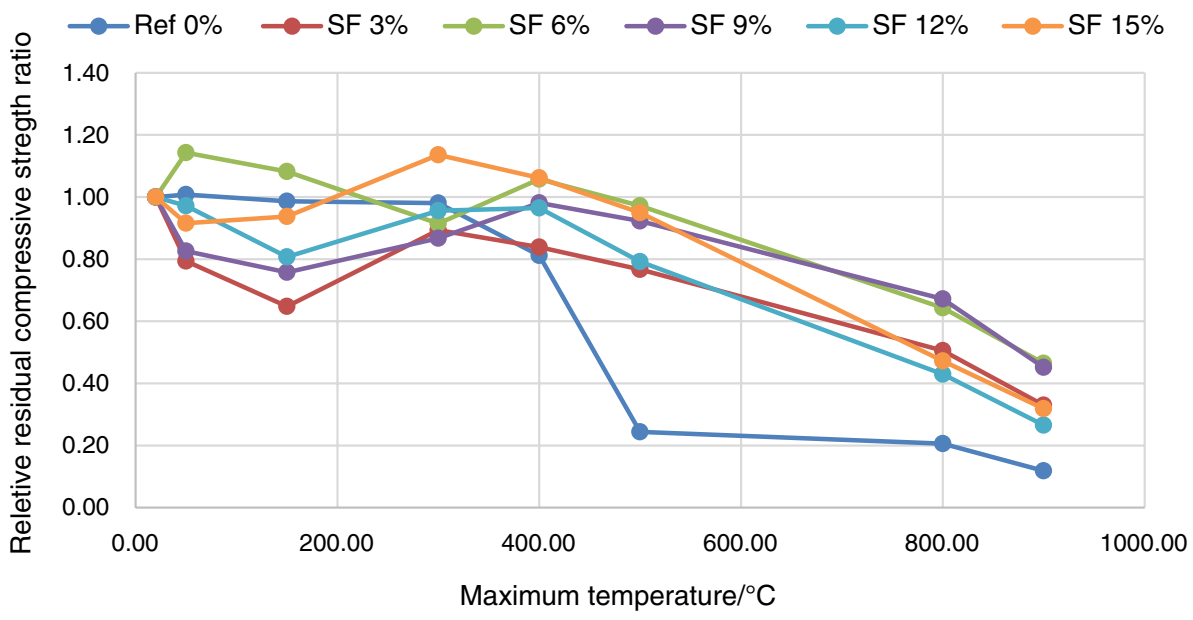

are presented herein. As illustrated in Fig. 10, different endothermic peaks are observed: (i) $20-200{ }^{\circ} \mathrm{C}$, (ii) $430-540{ }^{\circ} \mathrm{C}$, and (iii) $600-900^{\circ} \mathrm{C}$. The loss of mass appeared in the first peak is wider than the others, which is mainly due to evaporation of moisture from samples. The second endothermic peak (430-540 ${ }^{\circ} \mathrm{C}$ ) corresponds to the decomposition of $\mathrm{Ca}(\mathrm{OH})_{2}$ [26]. The third endothermic peak corresponds to the loss of water as a result of $\mathrm{CSH}$ decomposition and due to the decomposition of calcium-carbonate $\left(\mathrm{CaCO}_{3}\right)$ compound. Incorporation of MK, SF, and FA increases the mass loss due to evaporation of moisture. This performance could be related to the high absorption capacity of SCM powders. Less loss of mass was observed by the inclusion of the three SCM corresponds to the second peak, in which MK, SF, and FA consume $\mathrm{Ca}(\mathrm{OH})_{2}$ resulting in additional strength. Finally, the last peak indicates that the optimum replacements decrease the amount of $\mathrm{CaCO}_{3}$.

Generally, the effects of SCM on temperature resistance of HSCP properties are significant due to the pozzolanic activity that is based on the consumption of $\mathrm{Ca}(\mathrm{OH})_{2}$.

\section{SEM results}

Figure 11 shows the SEM images of the cement pastes made from OPC with and without SCM (MK, SF, and FA) at $20^{\circ} \mathrm{C}$ and $500{ }^{\circ} \mathrm{C}$. The reference mixture (0\% SCM) contains excessive amounts of hexagonal $\mathrm{Ca}(\mathrm{OH})_{2}$ in addition to rods of ettringite which produce a lot of pores and destruction after the exposure to elevated temperatures. The matrix containing pozzolanic materials shows denser microstructures with no presence of $\mathrm{Ca}(\mathrm{OH})_{2}$ which preserving the microstructure at elevated temperatures. This could be due to the high reaction of $\mathrm{Ca}(\mathrm{OH})_{2}$ with the pozzolanic materials [27]. Thereafter, forming more crystalline products to fill some pores and keep the structure coherent.

\section{Computed tomography results}

The results of $\mathrm{CT}$ analysis were obtained from a transverse cutting on the cylinder from the middle to figure out the pores in the inner side of the specimen structure. The CT photographs were captured for specimens' size
Fig. 7 Relative residual compressive strength of HSCP incorporated with FA as a function of the temperature

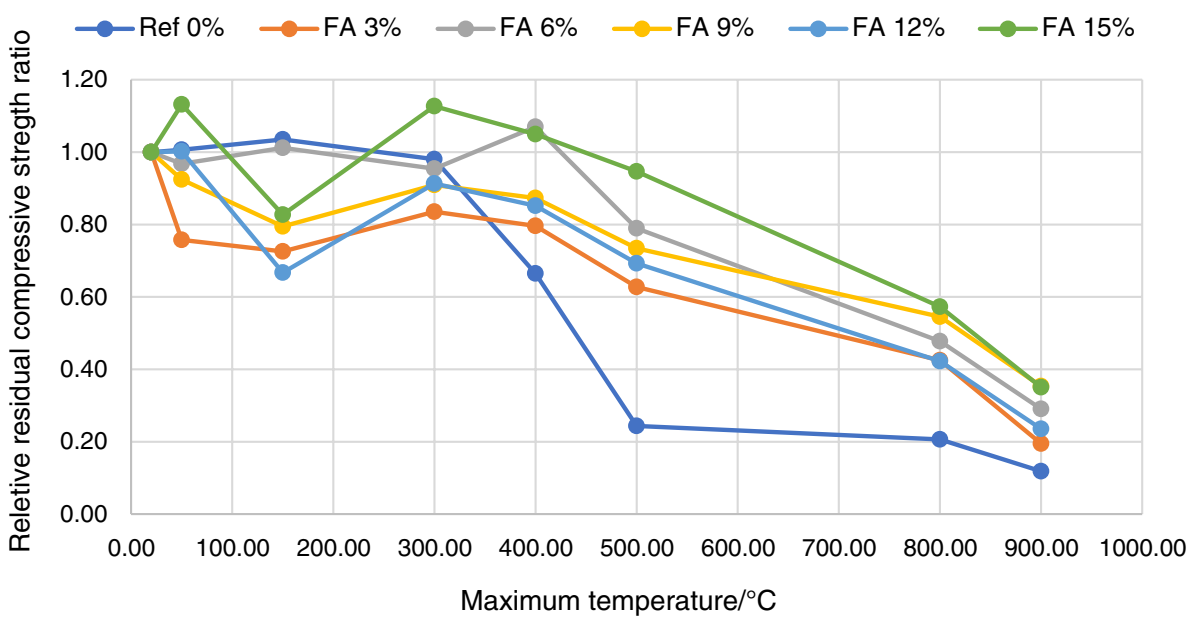


Fig. 8 Relative residual compressive strength of HSCP incorporated with $\mathrm{MK}$ as a function of temperature

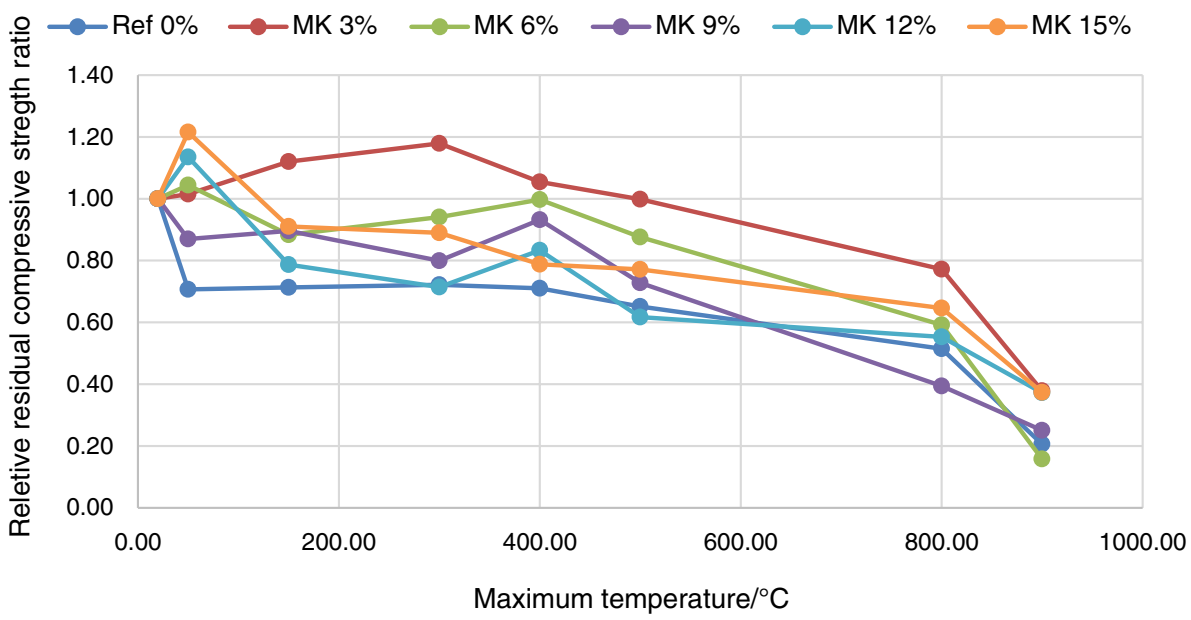

Fig. 9 Temperature resistance of relative residual compressive strength results of all tested mixtures $/ 20-900 /{ }^{\circ} \mathrm{C}$
Table 4 The optimal values of the used SCM (by cement replacement)

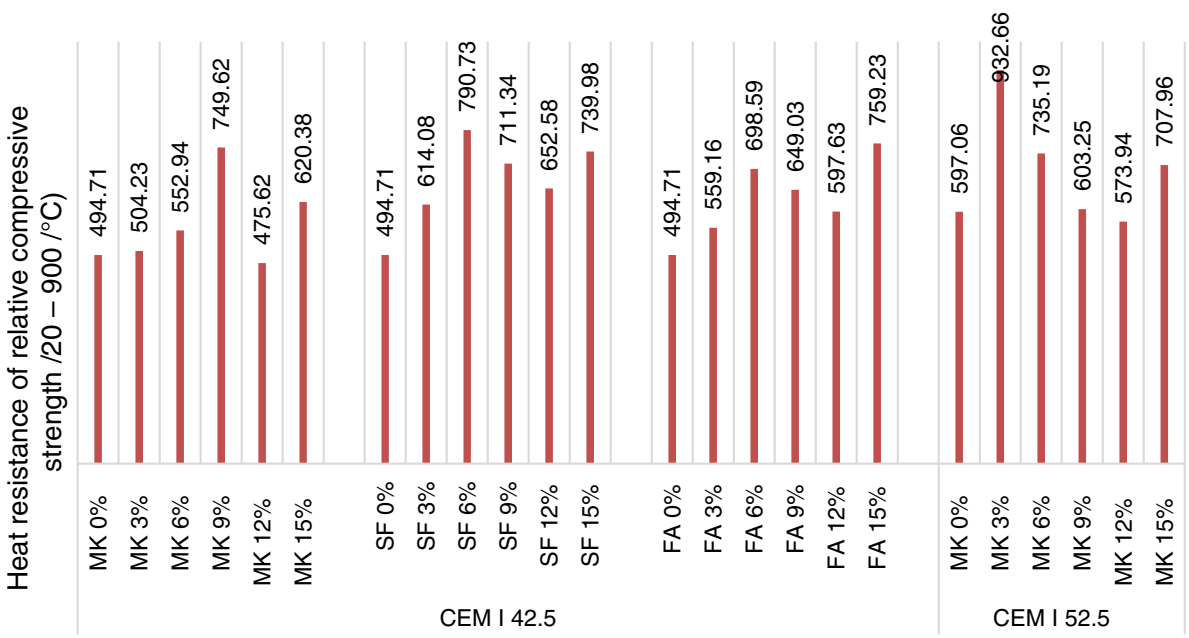

alteration and porosity enhancement take place by SCM, all together could produce a blended cement paste with less loss of strength after the exposure to elevated temperatures. The CT method is a suitable and accurate method to measure the pores through the cross-section in very thin slices.

\section{Conclusions}

This experimental study is related to the performance of high strength paste (HSCP) incorporated with different supplementary cementitious materials (SCM) after exposure to different levels of elevated temperatures. The SCM were metakaolin (MK), silica fume (SF), and fly ash (FA) by using the following replacements of cement: $0,3,6,9$, 12 and $15 \%$. Short incremental replacement is used in order to increase the accuracy for optimum replacement selection. The effects of changing the grinding fineness of cement 


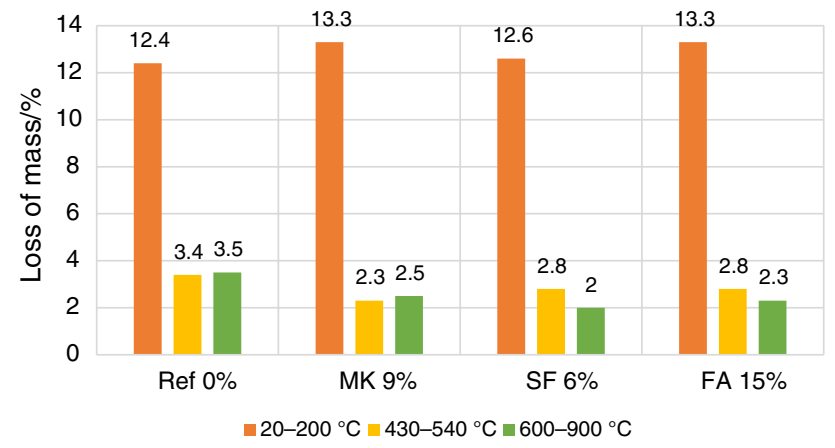

Fig. 10 Loss of mass of different phases using TG/DTA

have been studied as well as the mechanical and chemical properties after exposure to 50, 150, 300, 400, 500, 800 and $900{ }^{\circ} \mathrm{C}$. The results showed that incorporating MK, SF and FA has significant advantages for temperature resistance. The main following results could be drawn as follows:

1. Incorporating MK, SF or FA to cement increases the temperature resistance of HSCP based on their chemical compositions and their particles fineness.

2. Replacing of the cement (Type CEM I $42.5 \mathrm{~N}$ ) by 9\% of MK is the optimum replacement as far as the relative residual compressive strength is concerned, which improves the temperature resistance by $152 \%$ compared to the reference mixture ( $0 \%$ replacement).

3. The increase in the temperature resistance for SF mixtures reaches the maximum value when using $6 \%$ of $\mathrm{SF}$ to cement replacement. The increase of temperature resistance is by $160 \%$ compared to the reference mixture.

4. The increase in the temperature resistance for FA mixtures reaches the maximum value when using $15 \%$ of FA to cement replacement. The increase of tempera- ture resistance is by $153 \%$ compared to the reference mixture.

5. The comparison of the used SCM from the perspective of temperature resistance has been considered throughout the study. Results indicated that SF showed higher temperature resistance than MK and FA by about $8 \%$ and $7 \%$, respectively.

- The elevated-temperature performance of SCM changes by changing the grinding fineness of the cement. The study has been conducted only for MK, which is blended with two types of cement, i.e., CEM I $42.5 \mathrm{~N}$ and CEM I $52.5 \mathrm{~N}$.

I. The effect of cement fineness in the behaviour of the MK replacements is significant, the amount of optimum replacement of MK with CEM I $42.5 \mathrm{~N}$ is shifted from 9 to $3 \%$ by changing cement to CEM I $52.5 \mathrm{~N}$. This outcome is due to the high fineness of CEM I $52.5 \mathrm{~N}$, likewise the high fineness of MK, resulting in very dense microstructure, therefore limiting the contribution of MK.

II. In case of reference mixtures ( $0 \% \mathrm{SCM})$, mixtures of CEM I $52.5 \mathrm{~N}$ have shown higher temperature resistance than the mixtures of CEM I $42.5 \mathrm{~N}$. The increase in the temperature resistance reaches $120 \%$.

- Thermo-gravimetric findings support the positive contribution of MK. This result is promising for other SCM. Using SCM enhance the temperature resistance through pozzolanic activity by consumption, $\mathrm{Ca}(\mathrm{OH})_{2}$ which considers the main cause for deterioration. 
Fig. 11 The SEM images of HSCP with and without SCM at 20 and $500{ }^{\circ} \mathrm{C}$ for the results of optimum replacements
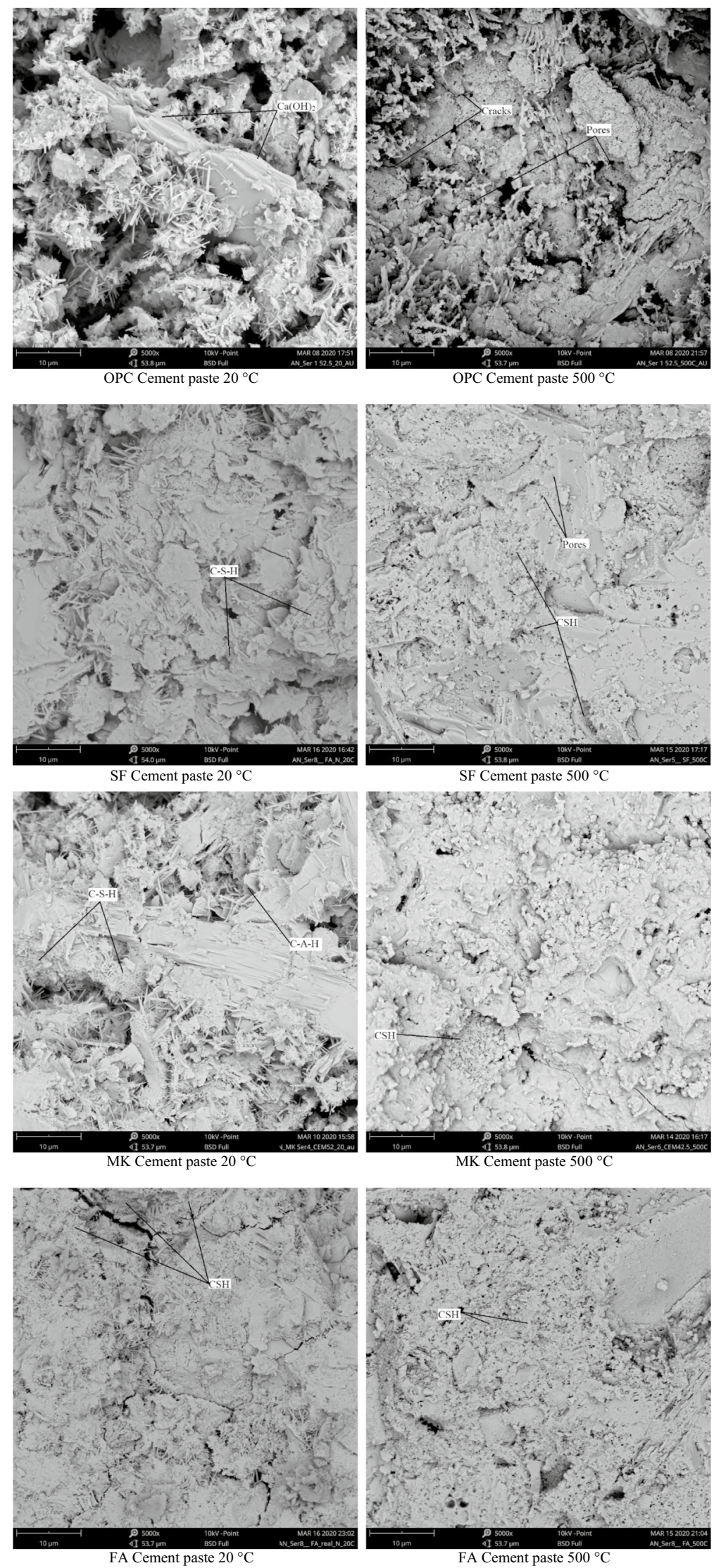


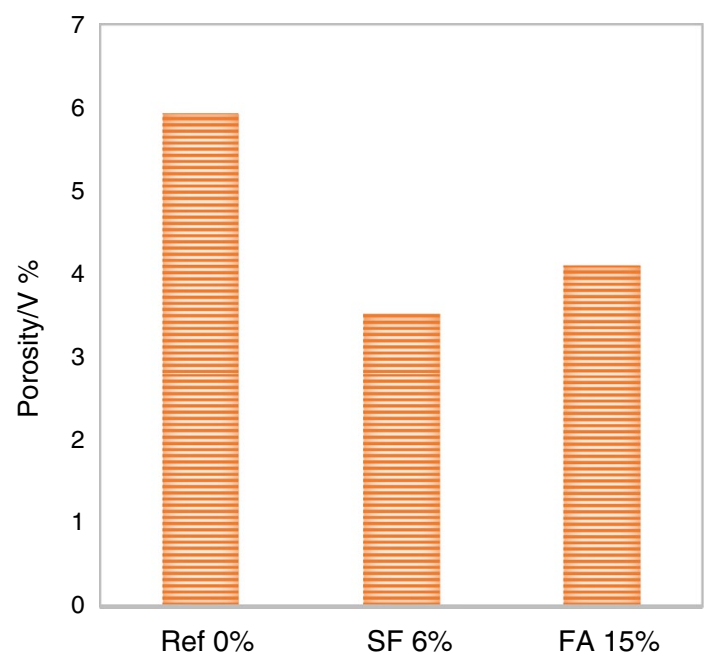

Fig. 12 Pores volume results of HSCP at the optimum replacements of SF and FA

- The mineralogical composition and microstructure for the optimum replacements were also studied using SEM technique at ambient and elevated temperatures.

- SEM results show that ordinary cement paste contains a lot of hexagonal shapes of $\mathrm{Ca}(\mathrm{OH})_{2}$, which destroys the microstructures after elevated temperatures.

- The morphology of powder particles has an effect on the replacement amount and temperature resistance, where SF is finer than the other SCM. This results in higher temperature resistance and at less replacement compared to the other SCM.

- The porosity development is investigated using CT, the comparison was taking place between the reference mixture $(0 \%)$ and the optimum mixtures of SF and FA. The pores content in volume decreased by SF and FA with $2.4 \%$ and $1.83 \%$ compared to the reference, respectively.

\begin{abstract}
Acknowledgements The authors of the paper thank the support of the research received through the project NVKP_16-1-0019 "Materials and Experimental Development of Concrete Products with High Resistance (Chemical Corrosion, Refractory and Antifreeze)". The authors wish to thank the "Université 8 Mai 1945 Guelma" as well. The research reported in this paper was supported by the Higher Education Excellence Program of the Ministry of Human Capacities in the frame of the Water sciences \& Disaster Prevention research area of the Budapest University of Technology and Economics (BME FIKP-VÍZ). The authors thank the support of the GINOP-2.1.2-8-1-4-16 research fund.
\end{abstract}

Funding Open access funding provided by Budapest University of Technology and Economics.
Open Access This article is licensed under a Creative Commons Attribution 4.0 International License, which permits use, sharing, adaptation, distribution and reproduction in any medium or format, as long as you give appropriate credit to the original author(s) and the source, provide a link to the Creative Commons licence, and indicate if changes were made. The images or other third party material in this article are included in the article's Creative Commons licence, unless indicated otherwise in a credit line to the material. If material is not included in the article's Creative Commons licence and your intended use is not permitted by statutory regulation or exceeds the permitted use, you will need to obtain permission directly from the copyright holder. To view a copy of this licence, visit http://creativecommons.org/licenses/by/4.0/.

\section{References}

1. Kawait T. State-of-the-art report on high-strength concrete in Japan-Recent developments and applications. In JSCE/VIFCEA Joint Seminar on Concrete Engineering. 2005:8-9.

2. Choe G, Kim G, Gucunski N, Lee S. Evaluation of the mechanical properties of $200 \mathrm{MPa}$ ultra-high-strength concrete at elevated temperatures and residual strength of column. Constr Build Mater. 2015;86:159-68.

3. Behnood A, Ziari H. Effects of silica fume addition and water to cement ratio on the properties of high-strength concrete after exposure to high temperatures. Cem Concr Compos. 2008;30(2):106-12.

4. Heikal M, El-Didamony H, Sokkary TM, Ahmed IA. Behavior of composite cement pastes containing microsilica and fly ash at elevated temperature. Constr Build Mater. 2013;38:1180-90.

5. Dinakar P, Sahoo PK, Sriram G. Effect of metakaolin content on the properties of high strength concrete. Int J Concr Struct Mater. 2013;7(3):215.

6. Saridemir M, Severcan MH, Ciflikli M, Celikten S, Ozcan F, Atis $\mathrm{CD}$. The influence of elevated temperature on strength and microstructure of high strength concrete containing ground pumice and metakaolin. Constr Build Mater. 2016;124:244-57.

7. Kalifa P, Menneteau FD, Quenard D. Spalling and pore pressure in HPC at high temperatures. Cem Concr Res. 2000;30(12):1915-27.

8. Hashimoto J, Takiguchi K. Experimental study on pullout strength of anchor bolt with an embedment depth of $30 \mathrm{~mm}$ in concrete under high temperature. Nucl Eng Des. 2004;229(2-3):151-63.

9. Lublóy É. Heat resistance of portland cements. J Therm Anal Calorim. 2018;132(3):1449-57.

10. Mendes A, Sanjayan J, Collins F. Phase transformations and mechanical strength of OPC/Slag pastes submitted to high temperatures. Mater Struct. 2008;41(2):345.

11. Xu Y, Wong YL, Poon CS, Anson M. Influence of PFA on cracking of concrete and cement paste after exposure to high temperatures. Cem Concr Res. 2003;33(12):2009-16.

12. Karakurt C, Topçu İB. Effect of blended cements with natural zeolite and industrial by-products on rebar corrosion and high temperature resistance of concrete. Constr Build Mater. 2012;35:906-11.

13. Hertz KD. Danish investigations on silica fume concretes at elevated temperatures. Mater J. 1992;89(4):345-7.

14. Poon CS, Azhar S, Anson M, Wong YL. Performance of metakaolin concrete at elevated temperatures. Cem Concr Compos. 2003;25(1):83-9.

15. Dias WPS, Khoury GA, Sullivan PJE. Mechanical properties of hardened cement paste exposed to temperatures up to $700 \mathrm{C} \mathrm{(1292}$ F). Mater J. 1990;87(2):160-6.

16. Hager I. Behaviour of cement concrete at high temperature. Bull Pol Acad Sci Tech Sci. 2013;61(1):145-54. 
17. Pacewska B, Wilińska I. Comparative investigations of influence of chemical admixtures on pozzolanic and hydraulic activities of fly ash with the use of thermal analysis and infrared spectroscopy. J Therm Anal Colorim. 2015;120(1):119-27.

18. Lin Y, Chen HL. Thermal analysis and adiabatic calorimetry for early-age concrete members. J Therm Anal Colorim. 2015;122(2):937-45.

19. Zhang YM, Napier-Munn TJ. Effects of particle size distribution, surface area and chemical composition on Portland cement strength. Powder Technol. 1995;83(3):245-52.

20. MSZ EN 196-2 Cement testing methods. Part 2: Chemical Analysis of cement. Budapest: Magyar Szabva'nyu"gyi Testu“let; 2013. (in Hungarian)

21. MSZ EN 525-12 Chemical analysis of cement. Part 12: Determination of free lime content. Budapest: Magyar Szabványügyi Testület; 2014. (in Hungarian)

22. BS EN 1008. Mixing water for concrete-Specification for sampling, testing and assessing the suitability of water, including water recovered from processes in the concrete industry, as mixing water for concrete; 2002.
23. ISO-834. Fire resistance test-elements of building construction, International Standard ISO384, Geneva, Switzerland, 1975

24. Eurocode 2. Design of concrete structures. Part 1 General rules structural fire design. EN 1992-1-2;2002, February 25.

25. Lublóy É, Kopecskó K, Balázs GL, Szilágyi IM, Madarász J. Improved fire resistance by using slag cements. J Therm Anal Colorim. 2016;125(1):271-9.

26. Lublóy É, Kopecskó K, Balázs GL, Restás Á, Szilágyi IM. Improved fire resistance by using Portland-pozzolana or Portlandfly ash cements. J Therm Anal Colorim. 2017;129(2):925-36.

27. Abdelmelek N, Lubloy E. Evaluation of the mechanical properties of high-strength cement paste at elevated temperatures using metakaolin. J Therm Anal Colorim. 2020;8:1-15.

Publisher's Note Springer Nature remains neutral with regard to jurisdictional claims in published maps and institutional affiliations. 